Revista Internacional de Apoyo a lalnclusión, Logopedia, Sociedad y Multiculturalidad.

Volumen 5, Número 2, Junio 2019, ISSN: 2387-0907.DOI: https://dx.doi.org/10.17561/riai.v5.n2.4

\title{
O vínculo mãe-bebê e o desenvolvimento dos transtornos alimentares sobre a óptica psicanalítica
}

(El vínculo madre y bebé y el desarrollo de los trastornos alimentarios sobre la óptica psicoanalítica)

\author{
Daniela Caroline Medeiros Ferreira \\ Universidade Uninassau, João Pessoa (Brasil) \\ mferreira.daniela@gmail.com
}

Fecha recepción: 01-03-2019

Páginas: 40-52

Fecha aceptación: 20-05-2019

\begin{abstract}
Resumo.
A relação mãe-bebê é essencial para o desenvolvimento da criança. Os autores Freud (1996), Winnicott (1999) e Melanie Klein (1996), descrevem sobre desenvolvimento infantil estabelecendo a relação mãe-bebê de acordo com os primeiros vínculos. Freud (1996) postulou a teoria da sexualidade e a dividiu em fases. Essas fases são em grau de importância todas com mesmo valor para 0 desenvolvimento da criança e a participação da mãe está presente em todos eles. No entanto, a falha na fase oral pode ser desencadeador de um Transtorno Alimentar (TA). Os transtornos alimentares trazem consequências negativas na relação mãe-bebê no aspecto da alimentação. $O$ trabalho aponta a relação que a criança terá com os alimentos sobre os reflexos do vínculo mãe e filho. O nosso objetivo foi conhecer a relação do papel da mãe para o surgimento dos TAs. Concluímos que de fato e de acordo com a psicanálise a atuação da mãe vai influenciar o surgimento ou não de um TA, as relações mães e filhas repletas de desvelo ou de desprezo fazem com que a criança através da alimentação excessiva ou da recusa dela ressignifique a maneira como a mãe cuidou do bebê nos primeiros anos de vida.
\end{abstract}

Palavras-chave: transtornos alimentares; infância; psicanálise

\begin{abstract}
.
The mother-baby relationship is essential for the child's development. The authors Freud (1996), Melanie Klein (1996), Winnicott (1999) describe about child development by establishing the mother-infant relationship in accordance with the first bonds. Freud (1996) postulated a theory of sexuality and divided into phases. These phases are in degree of importance all with the same value for the development of the child and the mother's involvement is present in all of them. However a flaw in the oral phase can be triggering of an eating disorder (TA).The Eating Disorders bring negative consequences in the mother-baby in the aspect power. The work shows the relationship that the child will have with food on the reflexes of the link between mother and son. Our objective was to determine the relationship of the role of the mother for the emergence of TAs. We conclude that in fact and according to the psychoanalysis, the mother's performance will influence the emergence or not in the TA, relations between mothers and daughters with full of care or contempt make the child through the excessive feed or the refusal of her resignify how the mother took care for the baby in the early years of life.
\end{abstract}

Key words: eating disorders; childhood; psychoanalysis 


\section{1.-Introdução.}

Os autores Freud (1996), Winnicott (1999) e Melanie Klein (1996), descrevem sobre desenvolvimento infantil estabelecendo a relação mãe-bebê de acordo com os primeiros vínculos. O elo entre uma mãe e o filho é o alimento que tem um significado psíquico, não apenas para a saciação da fome, mas sim induz o melhor contato evitando futuras frustações. As teorias psicanalíticas compreendem que 0 que contribui para um bom desenvolvimento da personalidade do indivíduo é a relação da mãe com o recém-nascido (Ávila, et al., 2007).

Neste caso uma boa qualidade no vínculo mãe-bebê torna saudável 0 desenvolvimento cognitivo e social da criança, caso não ocorra esta relação de maneira satisfatória o indivíduo terá um menor controle do ego, relacionando assim aos transtornos alimentares. A mãe é quem sacia o bebê desde a sua concepção e do mesmo modo depois que nasce; a mãe é reconhecida como um objeto psíquico pelo 0 filho.

O trabalho aponta a relação que a criança terá com os alimentos sobre os reflexos do vínculo mãe e filho. De acordo com o tema foi necessário: compreender as fases de desenvolvimento de uma criança, identificar a relação e características do vínculo mãe-bebê-alimento, conhecer características de alguns distúrbios alimentares na primeira infância. Destacando a libido é a importância da sexualidade infantil e a relação de amor e ódio pelo aspecto alimento vínculo, dando importância á pulsão oral.

Os transtornos alimentares trazem consequências negativas na relação mãe-bebê no aspecto da alimentação. O excesso ou escassez do alimento representa a presença do amor materno. O seio da mãe é para o bebê winnicottiano mais que apenas um objeto ou algo bom ou mal, de acordo com Loparic (2009), seio bom é o nome dado a uma "técnica", que aborda em sua teoria três metas: maternagem suficientemente boa e a alimentação satisfatória, e a interação das duas, introduzidas primeiramente no ambiente e, por conseguinte na mente do bebê.

O nosso principal objetivo foi conhecer o desenvolvimento afetivo da relação mãe e filho sob os aspectos psicológico e avaliar a influência da figura materna no desenvolvimento dos transtornos alimentares. Os objetivos específicos foram: analisar a relação mãe - bebê - alimento; verificar o desenvolvimento dos transtornos alimentares na primeira infância; explicar o transtorno alimentar sob a ótica psicanalítica, pois a psicanálise de Freud (1996) observou e sublinhou as relações libidinais da criança com o seio materno, para ele os transtornos alimentares estão centrados nos investimentos primitivos de intercâmbio alimentar e de sua relação objetal. (Kelner, 2004).

Este trabalho se justifica pela importância que traz a respeito dos conteúdos que abordam os transtornos alimentares; pois atualmente 0 número de pessoas apresentando algum tipo de transtorno tem crescido assustadoramente, e conhecer 
através de uma análise psicanalítica como se desencadeiam esses transtornos vai favorecer a classe acadêmica no campo da Psicologia e nas demais áreas de saúde que se propõem a conhecer e estudar esse fenômeno. 0 problema que ele se propõe a responder é qual a relação dos cuidados maternos com o desenvolvimento dos transtornos alimentares na visão psicanalista? Assim buscaremos na literatura artigos, teses, livros e textos que falem especificamente relação mãe-bebê-alimento; o desenvolvimento dos transtornos alimentares na primeira infância; e que expliquem o transtorno alimentar sob a ótica psicanalista.

O Corpus utilizado para a construção desde estudo de natureza bibliográfica sistemática foi composto por livros, artigos de natureza acadêmica e matérias veiculadas em sites especializados sobre o tema que abordam o vínculo mãe-bebê e 0 desenvolvimento dos transtornos alimentares sob uma perspectiva psicanalítica. Foi utilizada a técnica de fichamento literário (autor, ano) em que foram catalogadas as referências bibliográficas e os tópicos pertinentes ao tema da presente pesquisa, tendo como base de dados: SCIELO, LILACS, IBICT.

\section{2.-Desenvolvimento Infantil.}

Freud (1996) elaborou uma teoria sobre a sexualidade e classificou 0 desenvolvimento sexual em cinco fases: oral, anal, fálica, latência e genital.

Fase Oral - O bebê a princípio não se diferencia de sua mãe, sentindo-se ligado a ela, como se ambos fossem uma só pessoa. A comunicação do bebê com o mundo se dá através da boca, pela sucção e pelo choro. A amamentação, o hábito de chupar o dedo ou a chupeta, a necessidade de colocar tudo na boca e o desejo de morder, tudo isso é representativo do prazer que o bebê sente na região oral. (Taquette, 2008)

Fase Anal - Durante o segundo ano de vida a criança se desliga parcialmente das necessidades orais, passando a se concentrar em outras atividades recémadquiridas, a criança já tem condições para conter os esfíncteres, quando está acordada. Freud (1996) denominou esta etapa de "fase anal". Além da contenção dos esfíncteres a criança sente um grande prazer anal, principalmente no momento da defecação. (Taquette, 2008)

Fase Fálica - Esta fase se caracteriza por uma grande curiosidade sexual é o período em que ela descobre seus genitais, estes são explorados e manipulados. Freud (1996) denominou esta etapa da vida de "fase fálica", pois as sensações prazerosas estão localizadas no falo. Outro aspecto importante é que nesta fase a criança mostra preferência pelo genitor do sexo oposto, o menino tende a se aproximar apaixonadamente de sua mãe, tentando excluir o pai desta relação. A essa relação Freud (1996) denomina Complexo de Édipo. O menino teme ser castigado por desejar a exclusão do pai e perder seu pênis, o medo da castração; a menina, quando descobre que não tem pênis, demonstra sentimento de inferioridade. (Taquette, 2008) 
Fase de Latência - Nesta etapa as crianças já estão na escola, iniciando seu aprendizado formal. Grande parte da energia libidinal é deslocada para este aprendizado. A criança quando passa a conviver com outras sente muito prazer nas atividades em grupo, desligando-se parcialmente das questões relativas a seus genitais. $O$ período de latência se iniciaria quando o complexo de Édipo entra em declínio. Ao se desligar um pouco de suas tensões sexuais, a criança passa a se interessar pelo aprendizado da escola, que lhe possibilita a aquisição de novos conhecimentos e diferentes conquistas. (Taquette, 2008)

Fase Genital - O início da puberdade, com o estímulo dos hormônios sexuais ocorre uma intensificação das emoções sexuais. Com o desenvolvimento do corpo e dos órgãos genitais, há um aumento do desejo sexual. A prática da masturbação volta a ser frequente, no entanto, na fase pubertária, em que os órgãos genitais estão em desenvolvimento, os adolescentes se masturbam pensando em alguém, imaginando um ato sexual. É nesta fase que ocorre de fato o início da atividade sexual genital. (Taquette, 2008)

Outro ponto que a ser estudado são os estágios da evolução da libido. Podemos dar inicio do estágio da evolução da libido coma autoconservação, estágio delineado pela satisfação obtida no seio materno; 0 objeto de instinto é 0 alimento, porém 0 objeto de desejo é o seio materno. Quando esse objeto de desejo é abandonado ou retirado, o bebê passa ao autoerotismo, para Freud (1996), esta mudança de estágio é representada pelo chupar do dedo, um protótipo da sexualidade oral.

O narcisismo é a formação do eu que em alguns momentos se confunde com 0 próprio eu. Esta constituição do sujeito se dá pelo registro do simbólico e do imaginário. $O$ imaginário é o registro que se refere ao narcisismo primário e o registro simbólico pertence ao narcisismo secundário. A definição de narcisismo foi ganhando forma com o passar dos tempos, Freud (1996), porém, utilizou esse termo pela primeira vez no seu livro "Três Ensaios Sobre a Teoria da Sexualidade", no ano de 1905, para descrever aquele que toma a si mesmo como objeto sexual.

Desse modo, o conceito de Narcisismo reformula o conceito de objeto em psicanálise: a ideia de que só haverá objeto após a fase de escolha objetal deixa de ter sentido, já que há escolha de objeto na fase narcísica, o objeto é o próprio eu, o objeto da fase subsequente será um objeto externo, escolha que se dará com a dissolução do Complexo de Édipo. (Bento, 1999, p.1)

\section{1.-Vínculo mãe-bebê.}

Há uma relação com o corpo da mãe ainda na vida intrauterina e ao nascer ela experimenta sensações de incompletude, ao necessitar adaptar-se longe do metabolismo sanguíneo, desse momento até os dois meses de idade se instala 0 período narcisista primário. De acordo com Laender (2005, p. 64) "o narcisismo 
primário caracteriza-se pelas primeiras satisfações narcísicas, predominando a autossuficiência, ideal de toda perfeição".

Tanto na mãe como no bebê, pois surge a fantasia de imitar comportamentos maternos e ser doadora dos cuidados recebidos igual ao de sua mãe, e na criança as memórias ficaram gravadas numa forma de memória corporal na fase primária do inconsciente com desejos de ser completos e onipotentes. É o que se pode denominar de uma extensão do próprio self. Vale ressaltar que a libido e a agressividade já estão fundidas e presentes no inicio da vida do bebê, "O mundo de objetos da criança durante os primeiros dois ou três meses de vida consiste em partes gratificantes ou hostis e perseguidoras do mundo real" (Klein, 1996, p. 332).

Para a autora já existe uma ambivalência na fase oral cujo é representado pelo seio materno que projeta na criança uma relação de amor e ódio sendo colocados por Klein (1996) como seio bom e seio mau, que satisfaz ou frustra, podendo ser amado ou odiado. O seio mau na percepção da criança gera uma forma de ansiedade, faz que 0 bebê sinta ódio e queira destruir 0 objeto amado. Uma espécie de autoaniquilamento, daí o bebê sente-se culpado pelos impulsos destrutivos no objeto que ele depende gerando uma angústia que só será superada quando houver a introjeção do objeto bom de forma estável, que será o seio bom, que por sua vez é idealizado como protetor e consolador absoluto, levando a posicionar-se como objeto bom.

Nos primeiros anos de vida esse vínculo mãe-bebê ainda é influenciado pela inveja, interferindo na qualidade do relacionamento com a mãe. Klein (1996) coloca que a inveja citada se refere aquela sentida pelo bebê em relação á capacidade da mãe de sustentá-lo físico e emocionalmente, que nesse caso a inveja vem da ideia do amor, conforto e alimento estarem fora do próprio corpo. Até mesmo quando o bebê se sente gratificado pelo leite que surge com facilidade ele sente inveja, pois parece um dom inatingível. No entanto, Winnicott (1999) coloca outra visão ao que se refere ao seio bom, conforme descrito por Loparic (2009), o seio da mãe de que o bebê depende não é um objeto interno ou externo, bom ou mau. O seio bom é o nome dado a uma "técnica", a técnica que realiza três metas: maternagem suficientemente boa, a alimentação satisfatória, e a junção de ambas.

\section{2.-Relações Maternas e o Transtorno Alimentar.}

Os Transtornos Alimentares (TA) tem uma etimologia multifatorial, no entanto é comum classificar os fatores predisponentes, aqueles que aumentam as chances de surgimento da TA; os fatores precipitantes, que são os evidenciados pelos sintomas e os fatores mantenedores, estes vão determinar se o TA vai persistir ou desaparecer. (Morgan, Vecchiatti e Negrão, 2002).

Os fatores precipitantes podem ser descritos em três categorias: individual, familiar/hereditário e sociocultural. Os fatores individuais são os que nos interessa, pois ele apresenta em sua literatura os traços de personalidade e outros transtornos psiquiátricos. Indivíduos com Anorexia Nervosa (NA) geralmente apresentam traços 
como obsessividade, perfeccionismo, passividade e introversão, há uma associação da NA com o transtorno de personalidade obsessivo-compulsiva, ela também parece estar associada a quadros de ansiedade. (Morgan et all., 2002).

A Bulimia Nervosa (BN) apresenta características de personalidade diferentes da NA, ela geralmente está atrelada a sociabilidade, comportamento gregário, comportamento de risco e ansiedade. Esses comportamentos de riscos estão por sua vez associado à impulsividade e abuso de substância química. (Morgan ET all., 2002). Mas se nos ativermos aos conceitos gerais certamente cairemos no erro de não atingirmos o nosso principal objetivo, este envolve a relação da mãe com o filho e o possível aparecimento de um TA. A literatura já aponta a família como essencial para o desenvolvimento da criança.

O papel da família no desenvolvimento afetivo infantil é reconhecido há muito tempo na literatura psicológica, especialmente após a introdução do conceito freudiano de série complementar, segundo o qual a etiologia dos transtornos mentais repousaria na herança genética, na vida intrauterina, no trauma do nascimento mas, sobretudo, nas experiências da criança. (Barbieri, Jacquemin e Alves, 2005, p.117).

O vínculo mãe-bebê para alguns psicanalistas tem relações objetais, Freud (1996) observou que o seio materno para a criança é como viver uma experiência com um objeto que mais tarde vai ser reproduzido autoeroticamente. Para Winnicott (1999) a amamentação é uma fase de exemplo de mútuo entendimento, pois a mãe sabe 0 que o filho necessita e o filho sabe o que a mãe é capaz de fazer por ele (Gonçalves, Moreira, Trindade e Fiates, 2013).

No texto de Gonçalves, Moreira, Trindade e Fiates (2013), ele explica que, Klein (1996) acredita que o inconsciente da mãe e bebê está em uma mesma sintonia, relata sobre 0 seio bom e o seio mau. Ao longo da vida as crianças aprendem que para aliviar as tensões utiliza a comida, pois desde o seu nascimento foram ensinadas a receber 0 alivio pela boca através da mamada, dedos na boca e até mesmo pelas chupetas. Muitas vezes a criança que se recusa a se alimentar pode estar demonstrando uma carência de atenção da mãe, neste caso e de suma importância às reações dos pais quando uma criança tem dificuldades na alimentação.

O reprimido é, para nós, o protótipo do inconsciente. Percebemos, contudo, que temos dois tipos de inconsciente: um que é latente, mas capaz de torna-se consciente, e outro que é reprimido e não é em si próprio e sem mais trabalho, capaz de tornar-se consciente. (Freud, 1996, P.28). 


\section{3.-Transtorrnos alimentares na visão psicanalítica.}

Para Ávila et al. (2007), a interpretação dos transtornos alimentares traz a cena um complexo de identificações positivas e negativas referentes à estética e psicossocial da imagem do corpo.0 significado importante de experiências libidinais infantis, com o seu primeiro objeto de desejo que é o seio materno, Freud (1996) analisou e aprofundou ao seu conteúdo as fantasias e emoções nessas primeiras experiências relevando ao aspecto autoerótico na fase primitiva infantil. Freud (1996) acreditava que a criança não formasse relações com objetos nos primeiros anos de vida, mas diferenciou-a da relação objetal.

Todavia, todas as pessoas que sofrem de transtornos alimentares, colocam-se 0 problema na imagem do corpo, assim é associado esse intercâmbio entre mãe e filho, pois a mãe tem como exclusividade fazer o caminho da alimentação. As mães diante de qualquer demanda do bebê correspondem com alimentação, essa atitude não ensina a criança a distinguir a fome de outras sensações de desconforto, desta forma o individuo em sua fase adulta procurará no alimento preencher sensações de vazios no interior do seu eu, ou não procurará, isso vai depender da maneira como ele internalizou aquela primeira experiência da infância dentro de si. (Ávila, et al., 2007).

Essa internalização das sensações e experiências é o que gera ou não, na criança os transtornos alimentares. Entre os transtornos alimentares mais conhecidos destacamos neste trabalho, a anorexia em primeiro lugar, por ter sido ela o primeiro transtorno alimentar descrito no século XIX, a bulimia nervosa descrita em 1979, e a obesidade. A bulimia embora apresente diversas comorbidades semelhantes a anorexia, é ela a de maior incidência, sua ocorrência é de quase $90 \%$ dos casos em pessoas do sexo feminino; porém ambos os transtornos alimentares também se manifestam em homens, isso em números que vão aumentando a cada dia. Observa-se que a maioria dos transtornos alimentares se manifesta com maior frequência nos países industrializados. (Ávila, et al., 2007).

\section{4.-Abordagem psicodinâmica no tratamento dos transtornos alimentares.}

A origem dos transtornos alimentares pode ser de diversos: biológicos, psicológicos, familiares e socioculturais. Estes aspectos são considerados no momento da escolha do tratamento. Uma abordagem que apresenta resultados positivos é a psicodinâmica, ela está fundamentada em princípios da teoria psicanalítica, seu objetivo é orientar o paciente ao insight a fim de resolver os conflitos intrapsíquicos, reestruturando, organizando e desenvolvendo a personalidade. (Gorgati et al. 2002)

De acordo com Gorgati et al. (2002), psicanálise considera as relações infantis, e adeterminação inconscientede desejos, motivações ou medos no plano da ação. 0 campo de atuação nos transtornos alimentares se baseia nas teorias das pulsões, teoria das relações objetais, psicologia do ego,teoria do apego e a psicologia do self. 
Embora a teoria psicodinâmica não apresente uma definição conceitual única e precisa, ela tem o objetivo de auxiliar os pacientes a compreender os significados dos sintomas manifestos, encontrando assim alternativas mais adaptadas para lidar com 0 sofrimento psíquico. (Gogarti, et al.,2002, p. 44).

Para Gogarti et al. (2002), existe um leque de modelos de terapias considerados psicodinâmicos, elas podem ser conduzidas em grupo ou individualmente. Quando se trata de um quadro de anorexia geralmente a terapia é individual, ou uma terapia familiar. Ao que se relaciona a bulimia, não há estudos que comprovem o seu tratamento pelas terapias psicodinâmicas, porém as comorbidades podem ser tratadas dentro deste enfoque, na diminuição da ansiedade,nos traumas por abuso sexual e na melhora das relações interpessoais.

A anorexia pode ser tratada melhor tratada através de uma terapia individual; a participação da família é muito importante, o que pode ser sugerido uma terapia familiar, este tipo de terapia se mostra eficaz principalmente nos casos clínicos com menos de três anos. Foram observados melhora no quadro psicológico individual e nas funções familiares, isso citando os dois tipos de terapia, individual ou familiar. (Gogarti et al. 2002).

\section{5.-Resultados e discussão.}

Numa pesquisa no banco de dados da SciELO foram encontrados trezentos e onze artigos que abordam os transtornos alimentares e a aplicação da psicanálise. No entanto, para que a pesquisa fosse afunilada foram aplicados alguns filtros. 0 primeiro filtro utilizado foi 0 ano de publicação limitado a 2015, assim obtivemos vinte e sete artigos publicados; 0 segundo filtro foi a seleção da língua utilizada limitando-a as publicações em português e inglês. No entanto quando utilizamos os buscadores, transtorno alimentar e infância, esse número sofre uma diminuição para dez artigos.

Destas dez literaturas apenas um é relato de caso. A leitura dos resumos nos forneceu informações relevantes para a construção deste trabalho. Assim após avaliação destes foi necessário descartar três artigos, um por repetição e por tratar dos transtornos alimentares em homens trabalhadores da região Nordeste do pais e o terceiro por abordar a avaliação que psiquiatras fazem da relação CID-10 e DSMIV. Assim depois destas primeiras analises selecionamos no banco de dados do SciELO, cinco artigos relevantes para o nosso trabalho. Os dados encontrados coincidem com as ideias já expostas no corpo deste trabalho, a citar, a constituição da relação mãe-bebê e sua influencia para o desenvolvimento dos transtornos alimentares, a relação da comida com os transtornos, os abusos sexuais e sua influência no surgimento de TAs. 
Revista Internacional de Apoyo a lalnclusión, Logopedia, Sociedad y Multiculturalidad.

Volumen 5, Número 2, Junio 2019, ISSN: 2387-0907.DOI: https://dx.doi.org/10.17561/riai.v5.n2

Tabela1. Artigos selecionados no banco de dados SciELO.

\begin{tabular}{|c|c|c|}
\hline Artigo & AutorlAno & Conclusão do autor (es) \\
\hline $\begin{array}{l}\text { A } \\
\text { constituição } \\
\text { da relação } \\
\text { mãe-filha e o } \\
\text { desenvolvime } \\
\text { nto dos } \\
\text { transtornos } \\
\text { alimentares }\end{array}$ & $\begin{array}{l}\text { Moura; } \\
\text { Santos; } \\
(2017) \\
\frac{\text { Ribeiro. }}{2015}\end{array}$ & $\begin{array}{l}\text { Os resultados evidenciaram dificuldades de sustentação (holding) } \\
\text { por parte das mães, que acarretaram intenso sofrimento e } \\
\text { sentimento de impotência diante das necessidades básicas das } \\
\text { filhas. }\end{array}$ \\
\hline $\begin{array}{l}\text { Seletividade } \\
\text { alimentar: } \\
\text { uma } \\
\text { abordagem } \\
\text { nutricional }\end{array}$ & $\begin{array}{l}\text { Sampaio et al. } \\
2013\end{array}$ & $\begin{array}{l}\text { Embora a SA traga problemas de nutrição, elas não apresentam } \\
\text { nenhuma relação com os TAs. }\end{array}$ \\
\hline
\end{tabular}


Revista Internacional de Apoyo a lalnclusión, Logopedia, Sociedad y Multiculturalidad. Volumen 5, Número 2, Junio 2019, ISSN: 2387-0907.DOI: https://dx.doi.org/10.17561/riai.v5.n2

\begin{tabular}{|c|c|c|}
\hline $\begin{array}{l}\text { Transtornos } \\
\text { alimentares } \\
\text { na infância e } \\
\text { na } \\
\text { adolescência }\end{array}$ & $\begin{array}{l}\text { Gonçalves et } \\
\text { al. } \\
2013\end{array}$ & $\begin{array}{l}\text { Dentre os fatores de risco para os transtornos alimentares, } \\
\text { destacaram-se a mídia e os ambientes social e familiar. }\end{array}$ \\
\hline $\begin{array}{l}\text { Estudo de } \\
\text { caso controle } \\
\text { para avaliar o } \\
\text { impacto do } \\
\text { abuso sexual } \\
\text { infantil nos } \\
\text { transtornos } \\
\text { alimentares }\end{array}$ & $\frac{\text { Paraventi et }}{\underline{\text { al.2011 }}}$ & $\begin{array}{l}\text { Foi detectada uma forte relação entre os abusos sexuais infantis e } \\
\qquad \text { a anorexia nervosa. }\end{array}$ \\
\hline $\begin{array}{l}\text { Grupo } \\
\text { psicoeducativ } \\
\text { o multifamiliar } \\
\text { no tratamento } \\
\text { dos } \\
\text { transtornos } \\
\text { alimentares } \\
\text { na } \\
\text { adolescência }\end{array}$ & $\begin{array}{l}\text { Nicoletti et al. } \\
2010\end{array}$ & $\begin{array}{l}\text { A experiência com } \\
\text { grupopsicoeducativomultifamiliartemapontadoimportantesbenefício } \\
\text { snotocanteàinclusãodafamília no tratamento dos transtornos } \\
\text { alimentares. }\end{array}$ \\
\hline
\end{tabular}

Fonte: Autor (2019)

Os textos selecionados abordam as TAs explicando qual a sua relação com os cuidados maternos e com outros acontecimentos como o abuso sexual. Para Moura, Santos (2017) e Ribeiro (2015) a forma como a mãe se portou diante da filha nos seus primeiros anos de vida vai refletir no seu desenvolvimento e algumas vezes essa relação de desvelo da mãe pela filha pode trazer consequências como um TA.

Paraventi et al. (2011) relata que outro fator desencadeador de uma anorexia nervosa é o abuso sexual, ele chegou a essa conclusão após pesquisa de campo que apontou a NA como a de maior incidência sobre esse público.

No entanto Sampaio et al. (2013) nos apresenta outros fatores de risco para os TAs, ele nos cita a mídia por ela apresentar padrões de beleza quase inatingíveis e a família, histórico de mães com uma TA geralmente apresentam filhas com TA. Além dos padrões familiares exigidos.

Em contra partida Nicoletti et al. (2010) esclarece que a família pode ser um suporte no tratamento das TA, seu trabalho de pesquisa deixou claro a eficiência do trabalho realizado por um grupo psicoeducativo realizado no ambulatório do Programa de Atendimento, Ensino e Pesquisa em Transtornos Alimentares da IInfância e Adolescência - PROTAD, do Instituto de Psiquiatra do Hospital das Clínicas, da Faculdade de Medicina da Universidade de São Paulo.

\section{6.-Considerações Finais.}

Inicialmente responderei ao nosso principal objetivo que foi conhecer 0 desenvolvimento afetivo da relação mãe e filho sob os aspectos psicológico e avaliar 
a influência da figura materna no desenvolvimento dos transtornos alimentares. De fato o vínculo afetivo entre mãe e filho se forma com a criança ainda no ventre da mãe e perdura nos dois anos seguintes do nascimento. Para Freud (1996) a relação afetiva se inicia quando a mulher se descobre grávida e isto é perceptível até nas gravidezes indesejadas, para ele uma gravidez não é cem por cento em nenhum dos lados da emoção, a mulher não deseja totalmente como também não rejeita por inteiro, a gravidez inconscientemente é desejada e quando uma mulher engravida mesmo que conscientemente diga que não desejava, no seu inconsciente esse desejo já existia.

Assim as relações afetivas mãe e filho vão se formando e fortalecendo com 0 processo da gravidez. Quando a criança nasce se inicia um novo processo vincular, a mãe agora já não mais está com seu bebê imaginário, ela agora é cuidadora de um bebê real, essa ligação será imprescindível para o desenvolvimento psíquico da criança. A relação alimento, mãe e transtorno alimentar se inicia no primeiro ano de vida do bebê, por melhor dizer, na fase oral. A ingestão excessiva ou escassa de alimentos pode acarretar numa interpretação errada da criança. Nesta fase do desenvolvimento, conforme descrito por Freud (1996), a satisfação e insatisfação é alcançada com a boca. Através da boca a criança entra em contato com o mundo exterior.

A mãe, no entanto dá sua contribuição negativa neste processo. Algumas mães não sabem corresponder às demandas dos filhos e ofertam alimento a qualquer necessidade. $O$ desvelo da mãe pela filha também é um fator de risco, algumas meninas interpretam o desvelo como excesso e passam a negar-se a ingestão de alimentos (anorexia), expulsar por meio de vômitos ou laxantes (bulimia) ou ingerir alimentos mais que o necessário (obesidade).

Se observado a partir de uma ótica psicanalítica existe de fato uma ligação entre os vínculos afetivos da mãe com seu filho e o aparecimento dos TAs. A terapia psicodinâmica desenvolvida para atender pessoas com TA tem refletido positivamente no tratamento psicológico do sujeito. O que precisa ser reafirmado é que o TA não é um problema unicamente orgânico, ele apresenta seu lado psicológico para seu aparecimento, além do mais devemos pensar nos problemas psicológicos atuais, tendo em vista que uma pessoa com um TA pode sofrer preconceito e repressão.

Uma observação é que as literaturas sobre os TAs quase se dedicam aos casos nas idades adolescentes e adulta, o registro de literaturas destinadas unicamente ao tratamento dos TAs em crianças é muito acanhado. Esse trabalho teve algumas limitações, primeiro ele foi elaborado apenas com artigos, teses e dissertações que fossem na língua portuguesa, segunda limitação foi o pequeno número de publicações que tivessem como específico o surgimento dos TAs em crianças.

Acreditamos que esse trabalho servirá para abrir caminhos para outras pesquisas que desejem assim como nós conhecer o universo das crianças com TA. 


\section{7.-Referências.}

Ávila, A.C. L., Weiss, F.B., Laurindo, M.C. (2007). Relação mãebebê e seus reflexos na questão da alimentação na primeira infância. Akrópolis, Umuarama, v. 15, n. 3, p. 159-163, jul./set.

Barbieri, V., Jacquemin, A., Biasoli-Alves, Z.M.M. (2005). Personalidade materna e resultados de crianças no psicodiagnóstico interventivo: $O$ que significa mãe suficientemente boa. Revistas eletrônicas PUC Psico (PUC-RS) 36.2 (2005): 117-125.Disponível em: http://revistaseletronicas.pucrs.br/revistapsico/ojs/index.php/revistapsico.

Gorgati. S. B., Holcberg. A. S., Oliveira. M. D. (2002). Abordagem psicodinâmica nos transtornos alimentares. Revista Brasileira de Psiquiatria. vol.24, suppl.3, dez. Disponível em: http://www.scielo.br/scielo.php?script=sci_arttext\&pid=S151644462002000700010.

Gonçalves, J. de A.; Moreira, E. A. M.; Trindade, E. B. S. de M.; Fiates, G. M. R. (2013).Transtornos alimentares na infância e na adolescência. Revista Paulista de Pediatria, v. 31, n. 1, p. 96-103. Disponível em: < http://dx.doi.org/10.1590/S0103-05822013000100016>

Freud, S. (1996). Obras psicológicas completas de Sigmund Freud: O ego e o id e outros trabalhos (1923-1925). Vol. XIX. Rio de Janeiro: Ed. Imago.

Kelner, G. (2004). Transtornos alimentares: um enfoque psicanalítico. Estudos psicanalista, Belo Horizonte, n. 27, p. 33-44, ago. Disponível em $<$ http://pepsic.bvsalud.org/scielo.php?script=sci_arttext\&pid=S010034372004000100005\&lng=pt\&nrm=iso>.

Klein, M. (1996). Amor, culpa e reparação e outros trabalhos 1921-1945. Rio de Janeiro: Imago.

Laender, N.R. (2005). A construção do conceito de superego em Freud. Reverso 27. 52 , p. $63-68$.

Morgan, C.M., Vecchiatti, I.R., Negrão, A.B. (2002). Etiologia dos transtornos alimentares: aspectos biológicos, psicológicos e sócio-culturais. Revista Brasileira de Psiquiatria.

Nicoletti, M. et al. (2010). Grupo psicoeducativo multifamiliar no tratamento dos transtornos alimentares na adolescência. Psicologia em estudo, v. 15, n. 1.

Paraventi, F. et al. (2011). Estudo de caso controle para avaliar o impacto do abuso sexual infantil nos transtornos alimentares. Archives of Clinical Psychiatry. 
Sampaio, A.B.M. et al. (2013). Seletividade Alimentar: uma abordagem nutricional. Jornal Brasileiro de Psiquiatria.

Santos, R.S.G. (2017). A função materna e os problemas no desenvolvimento infantil. Universidade Regional Unijuí. Três Passos/ Rio Grande do Sul. Disponível em:

<http://bibliodigital.unijui.edu.br:8080/xmlui/handle/123456789/4317?show=ful

Taquette, S. (2008). Sexualidade na adolescência. Saúde do Adolescente: competências e habilidades. Brasilia: Ministério da Saúde. Saúde do portal.saude.gov.br, Brasília

Winnicott, D.W. (1999). Os bebês e suas mães. 2 ed. São Paulo: Martins Fontes. 